\title{
The Role of Membrane-Associated Iron-Binding Complex in Intestinal Iron Absorption in the Rat
}

\author{
Hideo Orimo, Sanae Hisayasu, Yukihiko Hirai, \\ and Yoshio Yoshino* \\ Department of Biochemistry and Molecular Biology, \\ Nippon Medical School, Bunkyo-ku, \\ Tokyo 113, Japan \\ (Received March 17, 1994)
}

\begin{abstract}
Summary A membrane-associated iron-binding complex was isolated from rat intestinal mucosa during iron absorption. Two ${ }^{59} \mathrm{Fe}$ peaks (peaks 1 and 2) were separated on Sepharose 6B gel filtration from detergent solubilized $20,000 \times g$ precipitate of upper intestinal mucosal homogenate after administration of ${ }^{59} \mathrm{Fe}$-labelled ferrous materials. Peak 1 was a membrane iron-binding complex whose apparent molecular weight was over $10^{6} \mathrm{Da}$ estimated by gel filtration, while peak 2 was identified as ferritin. Three major bands were detected on SDS-polyacrylamide gel electrophoresis (SDS-PAGE) of peak 1. The treatment of mucosal homogenate with $5 \mathrm{mM}$ ethylenediaminetetraacetic acid released ${ }^{59} \mathrm{Fe}$ binding from peak 1 . Incorporation of ${ }^{59} \mathrm{Fe}$ to peak 1 showed the maximum at $1 \mathrm{~h}$ and then reduced, while $\left[{ }^{59} \mathrm{Fe}\right]$ ferritin showed reciprocal behavior, which suggested that peak 1 may be a rapid turnover iron pool and transfer ${ }^{59} \mathrm{Fe}$ to ferritin. Peak 1 was also isolated from the brush border membrane and showed similar SDS-PAGE pattern to that from the $20,000 \times g$ precipitate of mucosal homogenate. Western blot analysis did not reveal immunoreactive transferrin in peak 1 . Those findings suggest that peak 1 may be a non-ferritin, non-transferrin iron-binding complex located on the brush border membrane and accept iron from the intestinal canal during iron absorption.
\end{abstract}

Key Words iron-binding complex, brush border membrane, iron absorption, transferrin, ferritin, rat

Iron nutrition is still unsatisfactory even in developed countries like Japan, especially in menstruating women (1). Since one of the reasons could be poor availability of iron in the food, the search of iron absorption mechanism should be helpful to improve iron status. Iron is absorbed mainly at the duodenum and the upper jejunum, and the amount of absorbed iron is controlled by the individual

* Present address: Showa Women's College, Setagaya-ku, Tokyo 154, Japan. 
need for the element (2). The iron absorption consists of two steps including the uptake to intestinal mucosal cells and release from the cells into the circulatory system. In the former step several transport systems participate depending on the chemical forms of iron and the latter step occurs by active transport across the basolateral membrane $(3,4)$. The forms of food iron are divided to heme and non-heme sources. Heme iron is absorbed more efficiently than non-heme iron via heme receptor on the brush border membrane (5) but then joins the same iron pool as non-heme iron in the mucosal cell. Non-heme iron in the intestinal lumen includes three forms, namely inorganic ferrous and ferric iron and several proteinbound irons such as transferrin- and lactoferrin-bound irons. The ferric iron is hardly dissolved in the intestinal canal at physiological $\mathrm{pH}$ so its absorption is extremely low. On the other hand, ferrous iron is fairly easily absorbed and shows saturable binding kinetics to brush border membrane vesicles, suggesting existence of a ferrous iron carrier $(6,7)$.

Transferrin-bound iron is also considered as a source of the absorption. The iron bound to serum transferrin is absorbed across the intestinal loop prepared at the duodenum (8), and the pancreatic juice contains transferrin in rats (9). The receptor assay suggested that the transferrin receptor on the brush border membrane (9) and immunohistochemical study revealed transferrin in the mucosal cells of rats (10). In mucosal cells, another iron-binding protein, ferritin, is localized and considered to be involved in iron absorption (11-13). Several investigators, however, have reported non-ferritin, non-transferrin iron-binding proteins. It is suggested that those proteins and protein complexes may be involved in iron absorption (14-18). We found a large molecular iron-binding complex on the brush border membrane and investigated several characteristics and roles of the complex during iron absorption.

\section{EXPERIMENTAL}

Animals. Male Wistar rats were obtained from Saitama Experimental Animals (Saitama, Japan) and were fed an iron-deficient diet which contained $5.5 \mu \mathrm{g}$ of iron/g (Oriental Yeast Co., Tokyo, Japan) for a week. The body weights of the animals were $250-400 \mathrm{~g}$.

Preparation of membrane extracts. After fasting overnight except supply of water ad libitum, rats were administered $0.6 \mathrm{ml}$ of radioactive iron solution consisted of $74 \mathrm{kBq}(2 \mu \mathrm{Ci}){ }^{59} \mathrm{FeCl}_{3}, 2 \mu \mathrm{mol} \mathrm{FeSO}_{4}, 2 \mu \mathrm{mol}$ sodium ascorbate per 100 $\mathrm{g}$ body weight, and $20 \mathrm{mg} / \mathrm{ml}$ of fructose via a stomach catheter. After $1 \mathrm{~h}$ of iron administration rats were sacrified by exsanguination from the abdominal aorta under ether anesthesia and a 20-cm length of the upper intestine measured from the pylorus, was removed. All of the following procedures were performed at $4{ }^{\circ} \mathrm{C}$. The intestines were slit lengthwise and rinsed with $200-300 \mathrm{ml}$ of ice-cold saline, and the mucosa was scraped off with a glass slide. The scraped mucosa was homogenized in 10 volumes of homogenizing buffer containing $0.25 \mathrm{M}$ sucrose, 0.1 
$\mathrm{mM}$ phenylmethylsulfonyl fluoride (PMSF) in $10 \mathrm{~mm}$ Tris- $\mathrm{HCl}, \mathrm{pH} 7.4$ by a Dounce homogenizer. The homogenate was centrifuged at $20,000 \times g$ for $30 \mathrm{~min}$ using SCR20B Himac Centrifuge (Hitachi Koki Co., Katsuta, Japan) and the resulting pellet was solubilized with $1 \%(\mathrm{v} / \mathrm{v})$ Triton $\mathrm{X}-100$ for $1 \mathrm{~h}$. The solubilized pellet was then centrifuged at $20,000 \times g$ for $30 \mathrm{~min}$ and the supernatant was removed as the Triton extract of the $20,000 \times g$ precipitate.

Brush border membrane was prepared by the method of Kessler (19) with slight modifications. Briefly, the scraped mucosa of iron-administered rats was homogenized in 10 volumes of homogenizing buffer in a Waring blender $(2 \mathrm{~min}$ at full speed) and added solid $\mathrm{CaCl}_{2}$ to $10 \mathrm{mM}$. After centrifuging at 3,000 $\times g$ for 15 min, the supernatant was centrifuged at $27,000 \times g$ for $30 \mathrm{~min}$ and the resulting pellet was homogenized in $40 \mathrm{ml}$ of the homogenizing buffer with a Potter-Elvehjem homogenizer. The homogenate was recentrifuged at $27,000 \times g$ for $30 \mathrm{~min}$ and the pellet (brush border membrane) was solubilized with $1 \%$ Triton X-100, centrifuged at $20,000 \times g$ for $30 \mathrm{~min}$ and the supernatant was removed as the Triton extract of brush border membrane.

Gel filtration. The Triton extracts were applied on Sepharose 6B column (Pharmacia Biotech, Uppsala, Sweden, column sizes were $5 \times 72 \mathrm{~cm}$ for the 20,000 $\times g$ precipitate and $2 \times 82 \mathrm{~cm}$ for the brush border) and eluted with $0.5 \%$ Triton $\mathrm{X}$ $100,50 \mathrm{~mm} \mathrm{NaCl}$, and $0.1 \mathrm{~mm}$ PMSF in $10 \mathrm{~mm}$ Tris- $\mathrm{HCl}, \mathrm{pH} 7.4$ (the eluting buffer).

Antibodies. Anti-rat liver ferritin and anti-rat serum transferrin antisera were raised in rabbits. Nonimmune rabbit serum was used as a control. Immunoprecipitation was carried out according to the method of Yoshino et al. (20). The Triton extract was dialyzed against the eluting buffer without Triton X-100 before the immunoprecipitation to dilute the Triton concentration.

Dot immunobinding assay. Dot immunobinding assay was performed by the method of Hawkes et al. (21) with slight modifications. The antigen was spotted onto a nitrocellulose membrane $(0.45 \mu \mathrm{m}$, Schleicher \& Schuell, Dassel, Germany). The nitrocellulose membrane was incubated with rabbit anti-rat serum transferrin antiserum diluted to $1: 1,250$. After the immunoreaction with the antibody, the membrane was incubated with biotin-conjugated goat anti-rabbit IgG (1:1,250, Sigma Chemical, St. Louis, MO, U.S.A.) then with avidin-labeled horseradish peroxidase $\left(1: 5,000\right.$, Sigma Chemical). Color reaction was developed with $3,3^{\prime}$ diaminobenzidine and $0.01 \%(\mathrm{v} / \mathrm{v})$ hydrogen peroxide.

SDS-polyacrylamide gel electrophoresis (SDS-PAGE) and Western blot. SDSPAGE with $7.5 \%$ polyacrylamide gel and 4-20\% gradient polyacrylamide gel (Daiichi Chemicals, Tokyo, Japan) was performed by the method of Laemmli (22). Western blot (23) was performed using Novablot semi-dry system (Pharmacia Biotech) and the same procedure as in the dot immunobinding assay.

Sucrose density-gradient isoelectric focusing. Sucrose density-gradient (5$50 \%)$ with $1 \%$ carrier ampholite ( $\mathrm{pH} \mathrm{2.5-4.0)}$ and $0.1 \%$ Triton X-100 was packed in LKB 8100 column $(110 \mathrm{ml})$. After sample was applied on the column, electro- 
phoresis was performed at $700 \mathrm{~V}$ for $40 \mathrm{~h} .{ }^{59} \mathrm{Fe}$ activity and $\mathrm{pH}$ were determined in each fraction $(1 \mathrm{ml})$.

Sucrose density-gradient centrifugation. A 10-40\% sucrose density gradient in $10 \mathrm{~mm}$ Tris- $\mathrm{HCl}(\mathrm{pH} \mathrm{7.4)}$ was prepared. Sample was applied on the densitygradient and centrifuged at $105,000 \times g$ for $6 \mathrm{~h}$ using RPS40 swing bucket rotor in 65P-7 Ultracentrifuge (Hitachi Koki).

Enzyme activities. Activities of p-nitrophenylphosphatase (EC 3.1.3.1) and succinate dehydrogenase (EC 1.3.99.1) were determined by the methods of Kowarski and Schachter (24) and Pennington (25), respectively.

Other methods. Protein concentration was determined by the method of Lowry et al. (26) with bovine serum albumin as a standard. For the Triton extract, the modified method (27) was employed.

The study protocol was approved by the Animal Ethics Steering Committee of Nippon Medical School.

\section{RESULTS}

\section{Isolation of iron-binding proteins from rat intestinal mucosa}

The Triton extract of the $20,000 \times g$ precipitate was applied on Sepharose $6 B$ columns. Figure 1 shows the elution pattern on Sepharose $6 \mathrm{~B}$ which separated two peaks of ${ }^{59} \mathrm{Fe}$, namely peak 1 and peak 2 . Peak 1 was eluted immediately after the void volume and apparent molecular weights of peaks 1 and 2 were estimated over $10^{6} \mathrm{Da}$ and $450 \mathrm{kDa}$, respectively, deduced from a set of standard proteins which consisted of cytochrome $c$ (molecular weight $12.5 \mathrm{kDa}$ ), bovine serum albumin $(67$ $\mathrm{kDa})$, catalase $(240 \mathrm{kDa})$, and ferritin $(450 \mathrm{kDa})$. In the immunoprecipitation

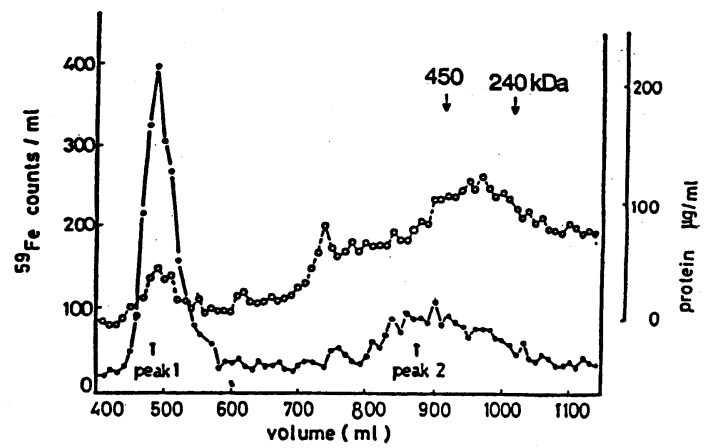

Fig. 1. Elution pattern of gel filtration on Sepharose $6 \mathrm{~B}(5 \times 72 \mathrm{~cm})$ for the Triton $\mathrm{X}-100$ extract of $20,000 \times g$ precipitate from rat upper intestinal homogenate $1 \mathrm{~h}$ after ${ }^{59} \mathrm{Fe}$ administration. The arrows indicate iron-containing fractions (peaks 1 and 2). Solid circle with solid line indicates ${ }^{59} \mathrm{Fe}$ activity and open circle with dotted line indicates protein concentration. Molecular weights were deduced from the standard proteins described in REsults. Eluting buffer was $0.5 \%$ (v/v) Triton X-100, $50 \mathrm{~mm} \mathrm{NaCl}$, and $0.1 \mathrm{~mm}$ PMSF in $10 \mathrm{~mm}$ Tris- $\mathrm{HCl}, \mathrm{pH}$ 7.4. 
Table 1. Immunoprecipitation of peaks 1 and 2 of the Triton X-100 extract of 20,000 $\times g$ precipitate with anti-rat liver ferritin and anti-rat serum transferrin.

\begin{tabular}{lcc}
\hline & Antiferritin (\%) & Antitransferrin (\%) \\
\hline Peak 1 & $5.7 \pm 2.5(5)$ & $5.2 \pm 7.0(9)$ \\
Peak 2 & $72.2 \pm 12.4(8)$ & $1.0 \pm 2.1(8)$ \\
\hline
\end{tabular}

Values (mean $\pm \mathrm{SD}$ ) are expressed as the percentage of ${ }^{59} \mathrm{Fe}$ precipitated with the antisera from ${ }^{59} \mathrm{Fe}$ in each peak for total ${ }^{59} \mathrm{Fe}$ activity of each peak. Numbers of determination are in parentheses.

Table 2. Time course of ${ }^{59} \mathrm{Fe}$ incorporation into peaks 1 and 2 of the Triton X-100 extract of $20,000 \times g$ precipitate.

\begin{tabular}{llcl}
\hline & \multicolumn{3}{c}{${ }^{59} \mathrm{Fe}$ incorporation $(\%)$} \\
\cline { 2 - 4 } & $1 \mathrm{~h}$ & $3 \mathrm{~h}$ & $5 \mathrm{~h}$ \\
\hline Peak 1 & 2.5 & 1.3 & 0.8 \\
Peak 2 & 2.0 & 4.4 & 8.2 \\
\hline
\end{tabular}

Values are means of two experiments and expressed as the percentage for total ${ }^{59} \mathrm{Fe}$ activity in the mucosal homogenate.

with anti-rat liver ferritin and anti-rat serum transferrin, peak 2 distinctly reacted with anti-ferritin but not with anti-transferrin, while peak 1 did not react with either antisera (Table 1). These results indicate that peak 2 was the ferritin fraction.

Time course of ${ }^{59} \mathrm{Fe}$ bound to the peaks

A time-course experiment was performed at 1,3 , and $5 \mathrm{~h}$ after iron administration. ${ }^{59} \mathrm{Fe}$ activities in peaks 1 and 2 on Sepharose 6B were compared (Table 2). ${ }^{59} \mathrm{Fe}$ in peak 1 showed the maximal value at $1 \mathrm{~h}$ and then reduced, while ${ }^{59} \mathrm{Fe}$ in ferritin fraction showed reciprocal behavior. In $20,000 \times g$ supernatant ${ }^{59} \mathrm{Fe}$ incorporation in the ferritin fraction was $11.7 \%$ at $3 \mathrm{~h}$ and $23.5 \%$ at $5 \mathrm{~h}$ for total radioactivity in the mucosal homogenate. These findings suggest that ${ }^{59} \mathrm{Fe}$ in peak 1 may transfer to ferritin.

\section{Characterization of peak 1}

Density of peak 1 estimated by the sucrose density-gradient centrifugation was 1.15-1.16. The isoelectric point of peak 1 estimated by sucrose density-gradient isoelectric focusing was $\mathrm{pH}$ 2.5. SDS-PAGE analysis revealed three major bands in the Triton extract which stained both with Coomassie brilliant blue and periodic acid Schiff (PAS) staining, suggesting glycoprotein bands (Fig. 2).

Effect of ethylenediaminetetraacetic acid (EDTA) on gel filtration pattern

When rat intestinal mucosa was homogenized with $5 \mathrm{~mm}$ EDTA in the 


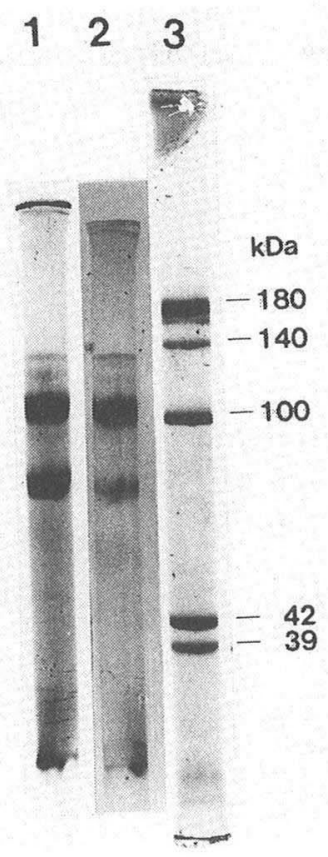

Fig. 2. SDS-PAGE pattern of peak 1. Peak 1 from the Triton X-100 extract of $20,000 \times g$ precipitate from rat upper intestinal homogenate $(1,2)$ was applied on $7.5 \%$ polyacrylamide SDS gels. Samples contained approximately $20 \mu \mathrm{g}$ of protein. Lane 1 was stained with Coomassie brilliant blue and lane 2 was stained with PAS. Both stains showed three major bands whose molecular weights were approximately 137,107 , and $78 \mathrm{kDa}$. Standard for molecular weight (RNA polymerase B subunits; 180, 140, 100, 42, and $39 \mathrm{kDa}$ ) is indicated in 3.

homogenizing buffer, the elution pattern of Sepharose 6B was changed as in Fig. 3. ${ }^{59} \mathrm{Fe}$ in peak 1 decreased extremely and the small molecular weight ${ }^{59} \mathrm{Fe}$ peak was observed. The apparent molecular weight of the third peak was smaller than 12.5 $\mathrm{kDa}$. This finding suggests that peak 1 has weaker affinity to iron than $5 \mathrm{~mm}$ EDTA.

\section{Isolation of iron-binding proteins from brush border membrane}

Brush border membrane was prepared and its purity was confirmed by the assay of marker enzymes, $p$-nitrophenylphosphatase for brush border membrane and succinate dehydrogenase for mitochondria. Purity of brush border membrane was 10.6-fold estimated by $p$-nitrophenylphosphatase activity but succinate dehydrogenase activity was 0.07 -fold compared with the homogenate.

The elution pattern of the Triton extract is shown in Fig. 4. Peak 1 was cleanly eluted but the ferritin peak was not clear. The dot immunobinding assay of the 


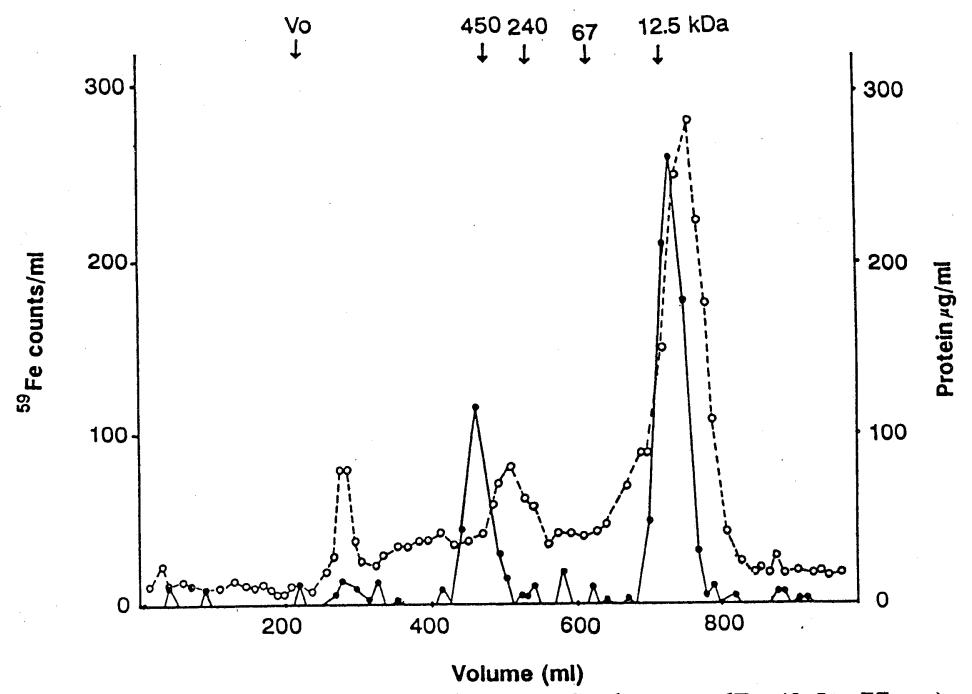

Fig. 3. Elution pattern of gel filtration on Sepharose $6 \mathrm{~B}(3.5 \times 77 \mathrm{~cm})$ for the Triton X-100 extract of $20,000 \times g$ precipitate from rat upper intestinal homogenate $1 \mathrm{~h}$ after ${ }^{59} \mathrm{Fe}$ administration when $5 \mathrm{~mm}$ EDTA was added to the homogenizing buffer. The eluting buffer and symbols are the same as in Fig. 1. $V_{\mathrm{o}}$ indicates the void volume. Molecular weights were deduced from the standard proteins described in Results. Peak 1 was hardly recognized and ${ }^{59} \mathrm{Fe}$ peak smaller than peak 2 was observed.

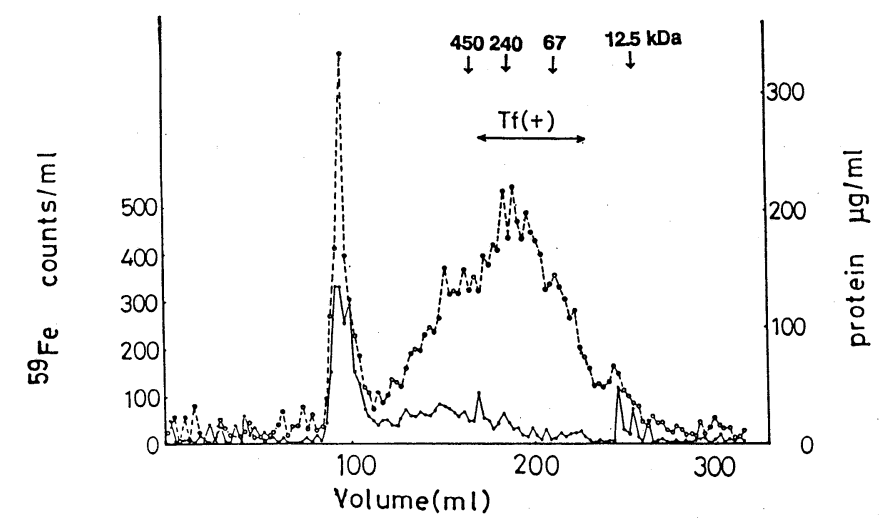

Fig. 4. Elution pattern of gel filtration on Sepharose $6 \mathrm{~B}(2 \times 82 \mathrm{~cm})$ for Triton X100 extract of the brush border membrane from rat upper intestinal homogenate. The eluting buffer and symbols are the same as in Fig. 1. Molecular weights were deduced from the standard proteins described in Results. The arrow with $\operatorname{Tf}(+)$ means positively reacted fractions with anti-rat serum transferrin. There was no ${ }^{59} \mathrm{Fe}$ activity in the transferrin fractions. 


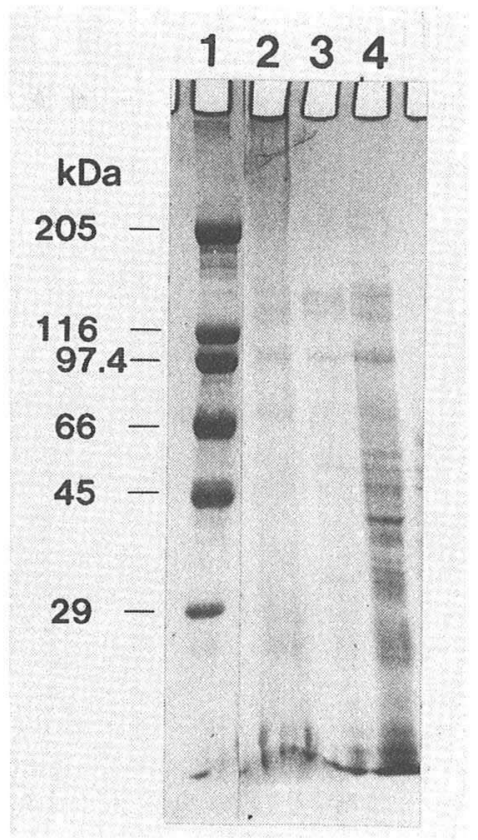

Fig. 5

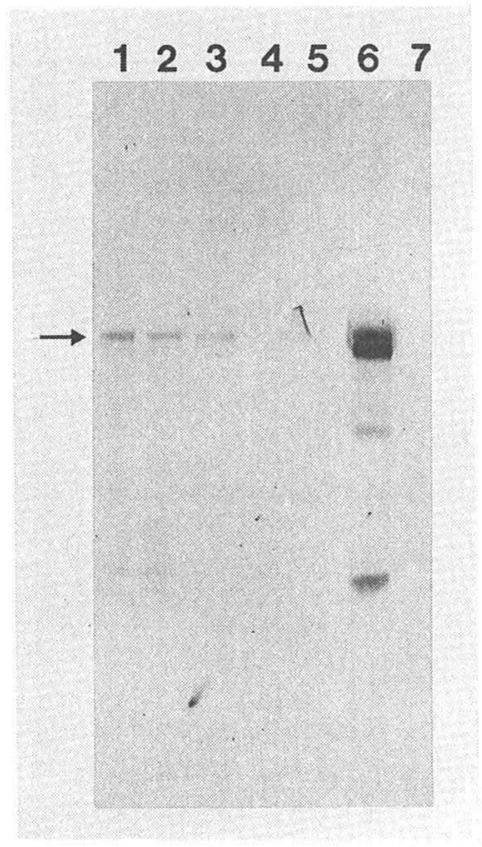

Fig. 6

Fig. 5. SDS-PAGE patterns of the brush border membrane and peak 1 derived from the membrane. Four to $20 \%$ gradient polyacrylamide SDS gel was employed and stained with Coomassie brilliant blue. Applied samples contained approximately $20 \mu \mathrm{g}$ of protein. Three major bands similar to those in Fig. 2 $(131,103$, and $80 \mathrm{kDa})$ were observed. Lane 1: standard for molecular weight (myosine, $205 \mathrm{kDa} ; \beta$-galactosidase, $116 \mathrm{kDa}$; phosphorylase $\mathrm{B}, 97.4 \mathrm{kDa}$; bovine albumin, $66 \mathrm{kDa}$; ovalbumin, $45 \mathrm{kDa}$; carbonic anhydrase, $29 \mathrm{kDa}$ ); lane 2: peak 1 from the Triton extract of the brush border membrane; lane 3: the Triton extract of the brush border membrane; lane 4: the brush border membrane.

Fig. 6. Western blot analysis using anti-rat serum transferrin. Samples (approximately $20 \mu \mathrm{g}$ protein) were applied on $4-20 \%$ gradient gel and immunoblot was performed as in EXPERIMENTAL. Lane 1: mucosal homogenate; lane 2: supernatant of $3,000 \times g$ centrifuge after adding $\mathrm{CaCl}_{2}$; lane 3: brush border membrane; lane 4: Triton extract of the brush border membrane; lanes 5 and 7: peak 1 of the Triton extract of the brush border membrane; lane 6: rat serum transferrin. The arrow indicates immunoreacting band. Lanes 1-4 and 6 showed a reaction with the antiserum but 5 and 7 did not.

Sepharose 6B fractions using anti-rat serum transferrin revealed the transferrin reactivity in smaller molecular weight fractions but apparently they did not bind ${ }^{59} \mathrm{Fe}$. SDS-PAGE analysis of peak 1 showed a pattern similar to that of peak 1 of the 20,000 $\times g$ Triton extract (Fig. 5). 


\section{Western blot analysis}

Homogenate, brush border membrane, and peak 1 of brush border membrane were analyzed by Western blotting using anti-rat serum transferrin. Homogenate and brush border membrane reacted with anti-transferrin but peak 1 did not react with the serum (Fig. 6). This finding suggests that peak 1 may not contain transferrin.

\section{DISCUSSION}

Iron binding proteins were isolated from detergent-solubilized $20,000 \times g$ precipitate of ${ }^{59} \mathrm{Fe}$-administered rat intestinal mucosa (Fig. 1). Peak 1 whose apparent molecular weight was over $10^{6} \mathrm{Da}$ was an acidic membrane protein complex and peak 2 was ferritin (Table 1). Peak 1 was contained in solubilized brush border membrane, however the $\left[{ }^{59} \mathrm{Fe}\right]$ ferritin peak was not detected in solubilized brush border membrane (Fig. 4). Peak 1 did not react with either anti-ferritin or anti-transferrin antiserum, indicating that peak 1 may be a nonferritin, non-transferrin iron-binding membrane protein complex. The time course experiment suggests that ${ }^{59} \mathrm{Fe}$ in peak 1 may transfer to ferritin and peak 1 may be a rapid-turnover iron pool (Table 2). These findings suggest that peak 1 localizes on the brush border membrane, binds iron in the lumen and transfers it to ferritin during iron absorption.

Peak 1 may contain ferrous iron because we administered ascorbic acid with iron solution, which converts ferric iron to the ferrous state and forms a soluble chelate with ferrous iron (28), but it is not clear whether the iron binds protein on the brush border membrane or phospholipids of the membrane. Peak 1 is a large molecular weight complex and it is likely that the complex contains membrane lipids and sugar moieties. Membrane phospholipids have a negative charge and possibly bind metal ions which have a positive charge like iron. Peters and co-workers suggested that membrane lipids have a role in iron absorption (29). Intraluminal iron-binding mucin has also been reported (30). This compound showed large molecular size $\left(>10^{6} \mathrm{Da}\right)$ and $1.33 \mathrm{~g} / \mathrm{ml}$ of density but could not be extracted by Triton X-100 and the mucin fraction did not contain protein detectable by SDS-PAGE. Those compounds could be contaminated in peak 1, however, iron binding to peak 1 seems specific since ${ }^{59} \mathrm{Fe}$ in peak 1 was transferred to ferritin in the time course experiment. Binding affinity of the ferrous iron to the complex could not be investigated in our in vivo model but weaker affinity than $5 \mathrm{~mm}$ EDTA was shown (Fig. 4). Recently, we found specific ferrous binding sites on the rat brush border membrane and showed that the dissociation constants of ferrous iron to rat brush border membrane were $0.25 \mathrm{nM}$ for the high-affinity site and $2.5 \mathrm{~nm}$ for the low-affinity site (unpublished observation). Binding of ferrous iron to brush border membrane vesicles has been studied using rabbits and mice and the results suggest the presence of a ferrous iron-binding carrier on the brush border membrane $(6,7)$. 
Non-ferritin, non-transferrin iron-binding substances in rats have been reported by several investigators. Yoshino and Manis found an iron binding substance from SDS-extract of $10,000 \times g$ precipitate of duodenal homogenate by gel filtration on Sephadex G-200 and suggested that this substance might be a labile iron pool (18). Yoshino and Hiramatsu also found that this substance was mainly mucosal ferritin (31). However they did not purify the protein completely and their "protein" seems to be a protein complex. In this study, although peak 1 is still a protein complex, we isolated peak 1 from ferritin and found that it localized on the brush border membrane.

Halliday and co-workers showed an ${ }^{59} \mathrm{Fe}$-binding peak which eluted at the void volume on Sepharose $6 \mathrm{~B}$ gel filtration from $10,000 \times g$ supernatant of rat duodenal homogenate. They showed the increase of the ${ }^{59} \mathrm{Fe}$ peak in iron deficient rats (17) but postulated that their peak was derived from the microsomal fraction. Other investigators also found large-molecular-weight iron-binding proteins $(14,15)$. Recent finding on non-heme iron uptake by IEC- 6 cells confirmed the presence of iron-binding proteins with apparent molecular weights of $120,95,55$, and $35 \mathrm{kDa}$ (32) in a subcellular vesicle fraction. Although the estimated molecular weights of candidates for the iron-binding sites are different from our results and they are not brush border proteins, their results show that there are several ferrous-binding proteins in the intestinal mucosal cells. In rabbit microvillus membrane, there is a report of high-molecular-weight iron-binding glycoprotein (33).

The existence of transferrin in intestinal lumen and mucosal cells was reported in rats $(8,10)$, although transferrin mRNA is not expressed in the mucosal cells (34). We previously showed transferrin receptors on the brush border membrane of rats (9), which is probably involved in receptor-mediated endocytosis of transferrin-bound iron. In this study, we also found transferrin immunologically on the brush border membrane but not in peak 1 (Fig. 6), suggesting that peak 1 may not contain transferrin receptors. The transferrin we found $\operatorname{did}$ not load ${ }^{59} \mathrm{Fe}$, which is inconsistent with the previous results. This discrepancy probably depends on the design of the experiments, since this study was performed in vivo while the transferrin receptor assay was in vitro. It is suggested that the absorption of transferrin-iron in vivo is not the main route of iron absorption, although we do not know the percentage of the protein-bound iron absorption in whole iron uptake. Further purification and characterization of peak 1 might answer those questions.

\section{REFERENCES}

1) Yoshino, Y., Sato, K., Orimo, H., Migita, S., Ikeda, Y., and Wakabayashi, S. (1988): Iron nutrition status among Japanese women. J. Nutr. Sci. Vitaminol. (Suppl.), 34, 67-70.

2) Wheby, M. S., Jones, L. R., and Crosby, W. H. (1964): Studies on iron absorption. Intestinal regulatory mechanisms. J. Clin. Invest., 43, 1433-1442.

3) Manis, J. G., and Schachter, D. (1962): Active transport of iron by intestine: Features 
of the two-step mechanism. Am. J. Physiol., 203, 73-80.

4) Manis, J., and Schachter, D. (1964): Active transport of iron by intestine: Mucosal iron pools. Am. J. Physiol., 207, 893-900.

5) Gräsbeck, R., Majuri, R., Kouvonen, I., and Tenhunen, R. (1982): Spectral and other studies on the intestinal haem receptor of the pig. Biochim. Biophys. Acta, 700, 137142.

6) Cox, T. M., and O'Donnell, M. W. (1981): Studies on the binding of iron by rabbit intestinal microvillus membranes. Biochem. J., 194, 753-759.

7) Muir, W. A., Hopfer, U., and King, M. (1984): Iron transport across brush-border membranes from normal and iron-deficient mouse upper small intestine. J. Biol. Chem., 259, 4896-4903.

8) Simpson, R. J., Raja, K. B,, and Peters, T. J. (1989): Mechanisms of intestinal brush border iron transport. Adv. Exp. Med. Biol., 249, 27-34.

9) Huebers, H. A., Huebers, E., Csiba, E., Rummel, W., and Finch, C. A. (1983): The significance of transferrin for intestinal iron absorption. Blood, 61, 283-290.

10) Hisayasu, S., Mugitani, K., Orimo, H., Ikeda, Y., Satoh, K., Hirai, Y., and Yoshino, Y. (1991): The role of diferric transferrin in iron absorption and transferrin concentration in rat pancreatic juice and milk. Int. J. Hematol., 54, 201-208.

11) Isobe, K., and Isobe, Y. (1983): Localization of transferrin in rat duodenal mucosa by immunoperoxidase technique. Acta Haematol. Jpn., 46, 797-807.

12) Granick, S. (1946): Ferritin IX. Increase of the protein apoferritin in the gastrointestinal mucosa as a direct response to iron feeding. The function of ferritin in the regulation of iron absorption. J. Biol. Chem., 164, 737-746.

13) Crosby, W. H. (1962): The control of iron balance by the intestinal mucosa. Blood, 22, 441-449.

14) Linder, M. C., and Munro, H. N. (1977): The mechanism of iron absorption and its regulation. Fed. Proc., 36, 2017-2023.

15) Pearson, W. N., and Reich, M. B. (1969): Studies of ferritin and a new iron-binding protein found in the intestinal mucosa of the rat. J. Nutr., 99, 137-140.

16) Worwood, M., Edwards, A., and Jacobs, A. (1971): Non-ferritin iron compound in rat small intestinal mucosa during iron absorption. Nature, 229, 409-410.

17) Halliday, J. W., Powell, L. W., and Mack, U. (1976): Iron absorption in the rat: The search for possible intestinal mucosal carriers. Br. J. Haematol., 34, 327-250.

18) Yoshino, Y., and Manis, J. (1973): Iron-binding substance isolated from particulate fraction of rat intestine. Am. J. Physiol., 225, 1276-1281.

19) Kessler, M., Acuto, O., Storelli, C., Murer, H., Müller, M., and Semenza, G. (1978): A modified procedure for the rapid preparation of efficiently transporting vesicles from small intestinal brush border membranes; Their use in investigating some properties of D-glucose and choline transport systems. Biochim. Biophys. Acta, 506, 136-154.

20) Yoshino, Y., Manis, J., and Schachter, D. (1968): Regulation of ferritin synthesis in rat liver. J. Biol. Chem., 243, 2911-2917.

21) Hawkes, R., Niday, E., and Gordon, J. (1982): A dot-immunobinding assay for monoclonal and other antibodies. Anal. Biochem., 119, 142-147.

22) Laemmli, U. K. (1970): Cleavage of structural proteins during the assembly of the head of bacteriophage T4. Nature, 227, 680-685.

23) Towbin, H., Staehelin, T., and Gordon, J. (1979): Electrophoretic transfer of proteins

Vol. 40, No. 6, 1994 
from polyacrylamide gels to nitrocellulose sheets: Procedure and some applications. Proc. Natl. Acad. Sci. U.S.A., 76, 4350-4354.

24) Kowarski, S., and Schachter, D. (1973): Vitamin D and adenosine triphosphatase dependent on divalent cations in rat intestinal mucosa. J. Clin. Invest., 52, 2765-2773.

25) Pennington, R. J. (1961): Biochemistry of dystrophic muscle: Mitochondrial succinate-tetrazolium reductase and adenosine triphosphatase. Biochem. J., 80, 649-654.

26) Lowry, O. H., Rosebrough, N. J., Farr, A. L., and Randall, R. J. (1951): Protein measurement with the folin phenol reagent. J. Biol. Chem., 193, 265-275.

27) Dulley, J. R., and Grieve, P. A. (1975): A simple technique for eliminating interference by detergents in the Lowry method of protein determination. Anal. Biochem., 64, 136-141.

28) Conrad, M. E., and Schade, S. G. (1968): Ascorbic acid chelates in iron absorption: A role for hydrochloric acid and bile. Gastroenterology, 55, 35-45.

29) Simpson, R. J., Moore R., and Peters, T. J. (1988): Significance of non-esterified fatty acids in iron uptake by intestinal brush-border membrane vesicles. Biochim. Biophys. Acta, 941, 39-47.

30) Conrad, M. E., Umbreit, J. N., and Moore, E. G. (1991): A role for mucin in the absorption of inorganic iron and other metal cations: A study in rats. Gastroenterology, 100, 129-136.

31) Yoshino, Y., and Hiramatsu, Y. (1974): Iron binding proteins found in duodenal mucosa of rats during iron transport. J. Biochem. (Tokyo), 75, 221-228.

32) Nichols, G. M., Pearce, A. R., Alverez, X., Bibb, N. K., Nichols, K. Y., Alfred, C. B., and Glass, J. (1992): The mechanisms of nonheme iron uptake determined in IEC-6 rat intestinal cells. J. Nutr., 122, 945-952.

33) O’Donnell, M. W., and Cox, T. M. (1982): Microvillar iron-binding glycoproteins isolated from the rabbit small intestine. Biochem. J., 202, 107-115.

34) Idzerda, R. L., Huebers, H., Finch, C. A., and McKnight, G. S. (1986): Rat transferrin gene expression: Tissue-specific regulation by iron deficiency. Proc. Natl. Acad. Sci. U.S.A., 83, 3723-3727. 